\title{
IMPACT OF PARENT'S DIVORCE ON CHILDREN'S EDUCATION FOR DISABILITY KIDS
}

\author{
${ }^{1}$ Gangsar Ali Daroni, ${ }^{2}$ Abdul Salim, ${ }^{3}$ Sunardi \\ ${ }^{1,2,3}$ Magister Pendidikan luar Biasa, Pascasarjana Universitas Sebelas Maret
}

\begin{abstract}
Children with special needs are children who have abnormalities in him, thus causing the individual has a need to be tailored to their specific characteristics. Abnormalities of children with special needs, impact on the immediate environment of children, namely family. Many cases of divorce in parents who have children with special needs. The cause may be possible because of negative parents' perceptions of children, low acceptance and resilience in parents with special needs children. Divorced parents have a negative impact on the education of children with special needs, because they lose the ability to fully play a parent in fulfilling the rights of the child. One solution in dealing with divorce that occurs in parents who have children with special needs is to use family counseling and divorce therapy. Handling is expected to minimize the negative impact of divorce parents of children with special needs and prevent the occurrence of divorce cases in other families who have children with special needs.
\end{abstract}

Keywords: children with special needs, divorced parent, education

\section{Latar Belakang}

Setiap manusia diciptakan Allah SWT dengan kelebihan dan kekurangan masingmasing, tak terkecuali bagi anak berkebutuhan khusus. Anak berkebutuhan khusus adalah anak yang secara signifikan mengalami kelainan/penyimpangan (fisik, mental-intelektual, sosial, dan emosional) dalam proses pertumbuhkembangannya dibandingkan dengan anak-anak lain yang seusia sehingga memerlukan pelayanan pendidikan khusus (Supriyanto, 2012: 1). Kelainan yang dimiliki oleh anak berkebutuhan khusus tersebut, tidak hanya berdampak kepada individu tersebut, namun juga berdampak terhadap lingkungan sosialnya baik dalam lingkup keluarga, maupun lingkungan masyarakat.

Keluarga merupakan lingkungan sosial terdekat dari anak berkebutuhan khusus. Orang tua yang tau bahwa dirinya memiliki anak berkebutuhan khusus, akan mengalami

\footnotetext{
* Corresponding author: Gangsar A. Daroni

Email: gangsaralidaroni@gmail.com

Published online at http://IJDS.ub.ac.id/2018

Copyright $\odot$ 2018PSLD UB Publishing. All Rights Reserved
}

berbagai masalah baik secara psikologi maupun sosial. Mereka cenderung memiliki perasaan malu yang mengakibatkan anak itu ditolak secara terang-terangan dan banyak keluarga yang menarik diri dari kegiatan-kegiatan masyarakat (Sidik, 2014: 2 ). Pengetahuan yang kurang terkait anak berkebutuhan khusus dan faktor sosial yang enggan menerima anak berkebutuhan khusus menyebabkan banyaknya kasus perceraian yang terjadi dikalangan orangtua yang memiliki anak berkebutuhan khusus.

Padahal hal tersebut dapat berdampak negatif terhadap perkembangan dan pendidikan anak berkebutuhan khusus. Orang tua cenderung tidak menganggap penting pendidikan bagi anak berkebutuhan khusus. Persoalan ini disebabkan banyak hal, disamping karena adanya faktor ketidak fahaman orang tua tentang pendidikan anak berkebutuhan khusus, rendahnya pendidikan orang tua, faktor lain yang justru lebih miris, ketika orang tua secara sadar dan sengaja tidak mau memperdulikan pendidikan anaknya, karena merasa khawatir, malu, dan menganggap 
sebagai aib mempunyai anak berkebutuhan khusus (Darmono, 2015: 2).

Kasih sayang dan dukungan dari kedua orang tua sangatlah penting bagi perkembangan anak berkebutuhan khusus. Mereka memerlukan perhatian yang extra dari kedua orang tuanya. Namun, apabila perceraian terjadi pada orang tua anak berkebutuhan khusus, tentu akan menyebabkan terhambatnya perkembangan dari anak berkebutuhan khusus.. Oleh karena itu, pada artikel ini akan membahas mengenai dampak perceraian orang tua terhadap pendidikan anak berkebutuhan khusus, dan salah satu alternatif solusi atas masalah-masalah tersebut agar anak berkebutuhan khusus dapat berkembang secara optimal. Meski ia memiliki keterbatasan yang disebabkan oleh kelainan yang mereka miliki, mereka juga memiliki potensi kemampuan yang dapat dioptimalkan untuk berprestasi.

\section{Pembahasan}

\subsection{Anak Berkebutuhan Khusus}

\section{Pengertian Anak Berkebutuhan Khusus}

Istilah anak berkebutuhan khusus merupakan istilah terbaru yang digunakan dan merupakan terjemahan dari Children with special need yang telah digunakan secara luas di dunia internasional. Ada beberapa istilah lain yang digunakan untuk menyebut anak berkebutuhan khusus, antara lain anak cacat, anak tuna, anak berkelainan, anak menyimpang dan anak luar biasa.

Menurut Suparno (2007: 1) anak berkebutuhan khusus (ABK) yaitu anakanak yang menyandang kecacatan tertentu (disable children) baik secara fisik, mental dan emosional maupun yang mempunyai kebutuhan khusus dalam pendidikannya (children with special educational needs). Pendapat lain menurut Abdullah (2013: 1) yang mengatakan bahwa anak berkebutuhan khusus adalah anak yang mempunyai kelainan/penyimpangan dari kondisi ratarata anak normal umumnya dalam hal fisik, mental maupun karakteristik perilaku sosialnya.

Sedangkan menurut Andesta (2017: 25) anak berkebutuhan khusus adalah anak yang mengalami kelainan dengan karakteristik khusus yang membedakannya dengan anak normal pada umumnya serta memerlukan pendidikan khusus sesuai dengan jenis kelainannya.

Dari beberapa pendapat ahli di atas, dapat disimpulkan bahwa anak berkebutuhan khusus adalah anak yang mengalami kelainan pada dirinya, sehingga menyebabkan individu tersebut memiliki kebutuhan yang perlu disesuaikan dengan karakteristik khusus yang mereka miliki.

\section{Klasifikasi Anak Berkebutuhan Khusus}

ABK terbagi menjadi beberapa ketunaan, antara lain: tunanetra, tunarungu, tunagrahita, tunadaksa, tunalaras, kesulitan belajar, gangguan perilaku, autis serta anak berbakat.

a. Tunanetra

Sunanto (2005: 184) mendefinisikan anak tunanetra ialah anak yang mengalami keterbatasan atau hambatan atau hal-hal yang tidak menguntungkan dalam menjalankan fungsinya sebagai akibat adanya gangguan pengihatan. Karena hambatan penglihatannya tersebut, mereka memiliki hambaran dalam berorientasi dan mobilitas. Dalam bermobilitas anak tunanetra sering menggunakan tongkat sebagai alat bantu untuk mengetahui keadaan lingkungan disekitarnya.

United Nations Educational, Scientific and Cultural Organization (UNESCO, 2015: 43) mengklasifikasikan anak tunanetra menjadi dua yaitu blindess dan low vision:

1) Blindness: A person who is blind has a total or high degree of vision loss. About $18 \%$ of blind people are totally blind - the remaining $82 \%$ can distinguish between light and dark.

2) Low Vision: Partial vision loss that cannot be corrected by ordinary visual devices (glasses or contact 
lenses) causes a visual impairment known as "low vision." A person with low vision has severely reduced visual acuity, asignificantly obstructed visual field, contrast sensitivity, or all three. The World Health Organization's definition of low vision is visual acuity less than $6 / 18$ and equal to or better than $3 / 60$ in the better eye with best correction.

Dapat dipaparkan secara jelas sebagai berikut: Klasifikasi pertama yaitu kebutaan. Seseorang dikatakan buta apabila memiliki kehilangan penglihatan keseluruhan atau hampir keseluruhan. Sekitar $18 \%$ dari orang buta yang benar-benar buta - sisanya $82 \%$ dapat membedakan antara terang dan gelap. Klasifikasi kedua yaitu kurang penglihatan. Kurang penglihatan yaitu kehilangan penglihatan yang tidak dapat dikoreksi dengan perangkat visual biasa (kacamata atau lensa kontak) menyebabkan gangguan penglihatan yang dikenal sebagai low vision telah sangat berkurang ketajaman matanya, bidang visual asignificantly terhalang, kontras sensitivitas, atau ketiganya. Definisi organisasi kesehatan dunia,low vision adalah ketajaman visual kurang dari 6/18 atau lebih baik dari 3/60 di mata dengan koreksi terbaik.

b. Tunarungu

Definisi tunarungu menurut Haenudin (2013: 56) yang mengatakan bahwa "tunarungu adalah seseorang yang mengalami kekuarangan atau kehilangan kemampuan mendengar baik sebagian atau seluruhnya yang diakibatkan karena tidak berfungsinya sebagian atau seluruh alat pendengaran, sehingga ia tidak dapat menggunakan alat pendengarannya dalam kehidupan sehari - hari yang membawa dampak dalam kehidupan secara komplek".

Anak tunarungu memiliki karakteristik yang khas aibat kelainan yang mereka miliki. Iswari (2007:61-68) mengungkapkan karakteristik anak tunarungu adalah sebagai berikut :

1. Karakteristik Inteligensi
Anak tunarungu memiliki inteligensi tinggi, sedang, dan rendah seperti anak normal pada umumnya.

2. Karakteristik dalam Segi Bahasa Anak tunarungu mengalami hambatan yang serius dalam berbahasa sehingga menjadi kendala dalam memahami pelajaran. Anak tunarungu mengalami kesulitan memahami kalimat bersusun atau kompleks.

3. Prestasi Akademik

Anak tunarungu memiliki masalah serius dalam berbahasa maka mereka juga mengalami hambatan dalam prestasi akademik.

4. Penyesuaian sosial dan pribadi

Kehilangan pendengaran mengakibatkan masalah dalam komunikasi, masalah komunikasi menyebabkan kesulitan sosial dan perilaku. Anak tunarungu menunjukkan karakteristik seperti kekakuan, egosentrik, tanpa control diri, impulsive, dank eras kepala.

c. Tunagrahita

Menurut Desiningrum (2016: 16) tunagrahita ialah anak berkebutuhan khusus yang memiliki keterbelakangan dalam intelegensi, fisik, emosional, dan sosial yang membutuhkan perlakuan khusus supaya dapat berkembang pada kemampuan yang maksimal.

Anak tuna grahita mengalami hambatan dalam bidang akademik maupun kemandirian dikarenakan kondisi kecerdasan yang berada di bawah rata-rata anak normal pada umumnya. Masalah ini berakibat pada perkembangan proses kemandirian dalam hidupnnya, apabila mereka tidak menguasai keterampilan dan kemandirian Bina Diri (Puspasari, 2012: 4).

d. Tunadaksa

Anak tunadaksa sering disebut cacat fisik atau kelainan fisik. "Anak tunadaksa dapat didefinisikan sebagai penyandang bentuk kelainan atau kecacatan pada sistem otot, tulang dan persendian yang dapat mengakibatkan gangguan koordinasi, komunikasi, adaptasi, 
mobilisasi, dan gangguan perkembangan keutuhan pribadi." (Astati, 2008: 3).

Karena hambatan fisik yang dialami oleh tunadaksa menyebabkan mereka memiliki hambatan dalam bermobilitas sehingga berdampak terhadap keterbatasan dalam melakukan aktifitas sehari-hari. Bina gerak dan pendidikan yang tepat diperlukan oleh anak tunadaksa.

e. Tunalaras

Anak tunalaras sering juga disebut anak tuna sosial karena tingkah laku anak ini menunjukkan penentangan terhadap norma-norma sosial masyarakat yang berwujud seperti mencuri, mengganggu, dan menyakiti orang lain. Dengan kata lain tingkah lakunya menyusahkan lingkungan (Rahman, 2015: 169).

Anak tunalaras memiliki gangguan dalam emosionalnya. Hubungan antara gangguan emosional dan tingkah laku dengan gangguan komunikasi cukup jelas. Anak atau remaja dengan gangguan emosional dan tingkah laku memiliki kesulitan yang besar dalam memahami dan menggunakan bahasa dalam lingkungan sosialnya (Desiningrum, 2016: 56).

f. Autis

Menurut Yuwono (2012:24), autis merupakan gangguan bagaimana anak melihat dunia dan bagaimana belajar melalui pengalamanya. Anak-anak dengan gangguan autis biasanya kurang dapat merasakan kontak sosial. Mereka cenderung menyendiri dan menghindari kontak dengan orang. Orang dianggap sebagai objek (benda) bukan sebagai subjek yang dapat berinteraksi dan berkomunikasi. Ada tiga gangguan pada anak autis yakni perilaku, interaksi sosial, dan komunikasi dan bahasa. Tiga gangguan ini memiliki saling ketertarikan

g. Anak Berbakat

Anak berbakat merupakan anak yang memiliki pemikiran kritis, mampu menerima informasi dengan mudah dan empunyai keterikatan terhadap tugas-tugas (Klein dalam Masruroh \& Widayat, 2014: 214). Renzulli (dalam Idrus, 2013: 118) mengidentifikasikan bahwa seorang anak yang dapat dikatakan sebagai anak berbakat jika is mempunyai: inteligensi yang tinggi di atas rata-rata (2) kreativitas yang tinggi; (3) komitmen pada tugas yang tinggi.

\subsection{Kasus Perceraian Orang Tua Yang Memiliki Anak Berkebutuhan Khusus}

Kelainan yang dimiliki oleh anak berkebutuhan khusus tidak hanya berdampak pada dirinya sendiri, namun juga berdampak kepada keluarga dari anak berkebutuhan khusus khususnya orang tua. Orang tua yang memiliki anak berkebutuhan khusus, akan mengalami berbagai masalah secara psikologis maupun sosial karena memiliki anak berkebutuhan khusus. Perasaan malu, pasangan yang kurang bisa menerima anak berkebutuhan khusus, dan berbagai faktor yang menyebabkan timbulnya maslah-masalah sosial dari orang tua yang memiliki anak berkebutuhan khusus. Salah satu masalah yang terjadi pada orang tua yang memiliki anak berkebutuhan khusus ialah kasus perceraian.

Kasus perceraian merupakan kasus yang banyak terjadi dikalangan orang tua yang memiliki anak berkebutuhan khusus. Hal itu sesuai dengan hasil penelitian dari Weiner (dalam Sobsey, 2004: 63) bahwa sekitar 70 persen pasangan di Amerika Serikat yang memiliki anak berkebutuhan khusus mengalami perceraian. Padahal tingkat perceraian untuk umum biasanya diperkirakan mencapai 50 persen. Penelitian lain yang dilakukan oleh Hartley et al. (2010) yang membandingkan kejadian dan waktu perceraian pada 391 orang tua anak-anak dengan gangguan spektrum autisme (ASD) dan sampel representatif yang sesuai dari orang tua anak-anak reguler menggunakan analisis kelangsungan hidup. Hasil penelitian menunjukkan bahwa orangtua anak-anak dengan ASD memiliki tingkat perceraian yang lebih tinggi daripada kelompok pembanding yaitu 23,5\% banding $13,8 \%$.

Dari beberapa penelitian tersebut dapat di ambil kesimpulan bahwa kasus 
perceraian orang tua yang memiliki anak berkebutuhan khusus termasuk dalam kategori tinggi. Hal tersebut dimungkinkan disebabkan oleh berbagai faktor seperti penerimaan diri orang tua yang rendah, resiliensi orang tua yang rendah dan persepsi orang tua yang masih negatife terhadap anak berkebutuhan khusus. Hal tersebut terbukti melalui penelitian dari Faradina (2016) mengenai penerimaan diri orang tua dengan anak berkebutuhan khusus, penelitian tersebut meunjukkan bahwa beberapa orang tua dengan anak berkebutuhan khusus memiliki penerimaan diri yang negatif terhadap anak berkebutuhan khusus dikarenakan anak yang lahir tidak sesuai dengan harapan dari orang tua.

Selain itu, menurut Anggraini (2013: 263) "orang tua anak berkebutuhan khusus juga masih memiliki persepsi negatif terhadap anak berkebutuhan khusus, dan menunjukkan sikap negatif terhadap ABK yaitu mengabaikan anak $\mathrm{ABK}$, kurang memberi perhatian, dan kasih sayang kepada anak, kurang berkomunikasi kepada anak, dan lain-lain". Penelitian dari Apostelina (2012: 172) juga menunjukkan bahwa keluarga yang memiliki anak autis memiliki resiliensi yang rendah. Keluarga belum dapat mengembangkan karakteristik coping-coherence yang baik, karena masih menyesali tiap hal yang terjadi di masa lalu dan belum bisa menerima kondisi anak sepenuhnya.

Dari pemaparan diatas dapat diketahui bahwa orang tua yang memiliki anak berkebutuhan khusus memiliki penerimaan diri dan resiliensi yang masih rendah, serta masih memiliki persepsi yang negatif terhadap anak berkebutuhan khusus. Hal tersebut berpotensi menjadi salah satu faktor yang menyebabkan banyaknya kasus perceraian yang terjadi di kalangan orang tua yang memiliki anak berkebutuhan khusus.

2.3. Dampak Perceraian Terhadap Pendidikan Anak Berkebutuhan Khusus

Keluarga nerupakan suatu sistem sosial yang dibentuk oleh sekumpulan tujuan, keyakinan kultural, peran orang tua dan anak, harapan, dan kondisi sosio ekonomi (Cook, Cook, \& Tran dalam Hidayati 2011: 14). Perkembangan anak berkebutuhan khusus dipengaruhi oleh lingkungan sekitarnya. Lingkungan sosial terdekat dari anak berkebutuhan khusus ialah keluarga (dalam konteks ini adalah orang tua). Orang tua memiliki peran yang begitu besar dalam perkembangan anak berkebutuhan khusus, baik dalam bidang pendidikan, sosial, emosional dan perilaku anak. Hal tersebut sesuai dengan penelitian dari Nandia (2015: 19) bahwa dukungan keluarga memiliki hubungan yang signifikan dengan kemampuan sosial dan emosional anak berkebutuhan khusus. Kemampuan sosial dan emosional yang rendah pada anak tunarungu dapat diminimalisir oleh keluarga, karena keluarga adalah orang yang paling dekat dan mempunyai intensitas tinggi untuk bersama dengan anak berkebutuhan khusus.

Menurut Darmono (2015: 1) Orang tua diharapkan berperan proaktif dengan banyak memberikan informasi kepada para guru, sehingga sangat membantu dalam mengembangkan bakat anak yang berkebutuhan khusus dapat berkembang secara optimal melalui program-program layanan yang dikembangkan oleh lembaga sekolah inklusif tersebut. Penelitian lain menurut Nasrawaty (2016: 60) bahwa orang tua memiliki 4 peran utama dalam mendidik anak berkebutuhan khusus, yaitu edukatif, sosialisasi, afeksi dan religius. Sedangkan menurut Millata (Tanpa Tahun: 1) kurangnya dukungan keluarga yang akan mengakibatkan anak kurang mendapat penyesuaian sosial yang baik, sehingga orang tua berperan memberi dukungan. Anak akan termotivasi untuk memperbaiki adaptasi mereka di masyarakat. Dari berbagai hasil penelitian diatas, dapat disimpulkan bahwa orang tua memiliki peran yang sangat penting dalam pendidikan anak berkebutuhan khusus.

Dalam beberapa kasus, orang tua anak berkebutuhan khusus mengalami perceraian yang menyebabkan kedua pasangan 
berpisah satu sama lain. Hal tersebut berdampak terhadap perkembangan anak berkebutuhan khusus begitu pula dalam pendidikannya. Penelitian dari Pollet (2010: 3) yang meneliti dampak perceraian pada keluarga anak berkebutuhan khusus, menunjukkan hasil bahwa di New York orang tua memiliki kewajiban untuk memberikan dukungan anak untuk anakanak mereka sampai usia 21. Dengan bercerainya orang tua, menyebabkan kewajiban tersebut sulit terpenuhi. Sehingga anak tidak terpenuhi hak untuk mendapat dukungan penuh dari kedua orang tuanya. Menurut Eymann, Busaniche, Llera, De Cunto, \& Wahren (2009: 547) perceraian orang tua yang memiliki anak berkebutuhan khusus menyebabkan menurunnya kualitas hidup anak berkebutuhan khusus usia sekolah.

Selain itu, perceraian orang tua juga berdampak pada pendidikan anak berkebutuhan khusus. Sesuai dengan penelitian dari Bernardi \&Radl (2014) Anak yang orang tuanya terpisah memiliki probabilitas mencapai gelar universitas yang rata-rata tujuh persen lebih rendah dari pada anak-anak dari keluarga utuh. Sedangkan menurut Yusuf (2014) Perceraian mempunyai pengaruh yang sangat besar terhadap perkembangan jiwa dan pendidikan anak, terutama anak usia Sekolah Dasar dan remaja. Diantaranya dapat menyebabkan anak bersikap pendiam dan rendah diri, nakal yang berlebihan, prestasi belajar rendah dan merasa kehilangan. Walaupun tidak pada semua kasus demikian tapi sebagian besar menimbulkan dampak yang negatif terhadap perkembangan jiwa anak dan juga berpengaruh terhadap proses pendidikan anak itu sendiri sebagaimana tersebut diatas.

Dari pembahasan diatas dapat disimpulkan bahwa perceraian orang tua berdampak negatif terhadap pendidikan anak berkebutuhan khusus. Oleh karena itu, Aniello \& Cipriani (2011: 61) menyarankan orang tua untuk memperhatikan agar anak berkebutuhan khusus tidak mendapat dampak negatif dari perceraian mereka. Dan lebih baiknya perceraian tidak terjadi mengingat hal tersebut dapat menyebabkan anak berkebutuhan khusus tidak mendapatkan kebutuhan yang seharusnya dapat dipenuhi melalui keluarga yang utuh.

\subsection{Solusi Penanganan Orang Tua Anak Berkebutuhan Khusus Yang Bercerai}

Dari pembahasan pada sub bab sebelumnya, dapat kita ketahui bersama bahwa perceraian orang tua yang memiliki anak berkebutuhan khusus berdampak negatif terhadap anak berkebutuhan khusus, terutama dalam pendidikannya. Oleh karena itu perlu dicarikan solusi dan alternative penanganan agar perceraian tersebut dapat hindari, jika sudah terjadi bagaimana agar dampak negatif pada perceraian itu dapat diminimalisir.

Salah satu alternatif penanganannya adalah dengan memberikan konseling keluarga kepada orang tua. Konseling keluarga atau family therapy adalah upaya bantuan yang diberikan kepada individu anggota keluarga melalui sistem kekeluargaan (pembenahan komunikasi keluarga) agar potensi yang dimiliki dapat berkembang secara optimal, sehingga dapat mengatasi masalah berdasarkan kerelaan dan kecintaan kepada keluarga (Sofyan dalam Novita, 2015: 19). Dalam penelitian yang dilakukan oleh Novita pada tahun 2015, konseling keluarga diterapkan untuk mengatasi kasus perceraian yang terjadi di Biro Konsultasi dan konseling Keluarga Sakinah Al-Falah Surabaya. Strategi yang digunakan dalam konseling keluarga ini yaitu mendengarkan, melihat, dan mendeskripsikan masalah, memberikan pandangan, menasehati, memberikan alternative solusi, memberikan arahan, memberikan motivasi, kemandirian, menggali informasi lain, dan memberikan solusi berdasarkan Al Quran dan sunnah.

Menurut Farida (2015: 84) konseling keluarga diharapkan dapat mengembalikan peran orang tua yang semestinya dapat membimbing proses pendidikan dan terapi anak agar dapat terpenuhi segala hak yang 
dimiliki anak. Jadi, konseling keluarga dapat dijadikan alternatif bimbingan bagi orang tua yang belum bercerai agar mencegah terjadinya perceraian. Kemudian untuk orang tua yang telah bercerai, konseling keluarga berfungsi untuk membimbing orang tua agar tetap berperan penuh sebagai orang tua untuk memenuhi hak anak berkebutuhan khusus agar perkembangan dan pendidikan anak tidak mengalami gangguan.

Selain konseling keluarga, penanganan yang dapat diberikan kepada orang tua dari anak berkebutuhan khusus yang telah bercerai ialah Divorce Therapy atau Terapi perceraian. Divorce Therapy adalah pengobatan yang bertujuan untuk memulihkan, mengembalikan dan mengkonfigurasi ulang hubungan keluarga dan fungsi orang tua, anak, saudara dalam menanggapi perpisahan. Terapi ini membantu keluarga mengubah cara mereka berhubungan, tingkat keintiman, derajat kekuasaan, dan peran anggotanya sehingga keluarga berfungsi lebih efektif (Issac dalam Green, 2010: 3).

Penanganan tersebut diharapkan dapat mengembalikan fungsi orang tua dalam keluarga seingga dapat berperan dalam mendidik anak berkebutuhan khusus sehingga meminimalisir dampak negatif yang terjadi pada kasus perceraian orang tua yang memiliki anak berkebutuhan khusus. Diharapkan kasus perceraian yang terjadi pada orang tua anak berkebutuhan khusus dapat diminimalisisr dan dicegah. Hal tersebut memerlukan kerjasama dari berbagai pihak mulai dari guru, terapis, psikolog, lingkungan terdekat dari keluarga, dan lain-lain untuk dapat memberikan pengetahuan kepada orang tua pentingnya dukungan keluarga terhadap perkembangan anak berkebutuhan khusus sehingga anak dapat berkembang secara optimal untuk memaksimalkan potensinya.

\section{KESIMPULAN}

Berdasarkan pembahasan di atas, dapat disimpulkan bahwa kasus perceraian pada orang tua yang memiliki anak berkebutuhan khusus tergolong tinggi. Penyebabnya bisa dimungkinkan karena persepsi orang tua yang negatif terhadap anak, penerimaan dan resiliensi yang rendah pada orang tua yang memiliki anak berkebutuhan khusus. Perceraian orang tua berdampak negatif terhadap pendidikan anak berkebutuhan khusus karena kehilangan kemampuan untuk berperan penuh sebagai orang tua dalam memenuhi hak anak.

Salah satu solusi dalam mengatasi perceraian yang terjadi pada orang tua yang memiliki anak berkebutuhan khusus adalah menggunakan konseling keluarga dan divorce therapy. Penanganan tersebut diharapkan dapat meminimalisir dampak negatif perceraian orang tua terhadap anak berkebutuhan khusus dan mencegah terjadinya kasus perceraian pada keluarga lain yang memiliki anak berkebutuhan khusus.

\section{SARAN}

1. Orang tua diharapkan dapat menerima anak berkebutuhan khusus dengan ikhlas, dan memiliki persepsi yang positif terhadap anak berkebutuhan khusus. Karena setiap anak diciptakan dengan kelebihan dan kekurangan masing-masing.

2. Guru, terapis, psikolog dan kepala sekolah diharapkan dapat berkerjasama untuk memberikan dukungan dan pengetahuan kepada orang tua tentang pentingnya dukungan keluarga terhadap perkembanan anak khususnya dalam hal pendidikan.

3. Lingkungan yang inklusif perlu dibentuk dalam masyarakat supaya tidak ada lagi persaan malu pada orang tua yang memiliki anak berkebutuhan khusus sehingga berpotensi menyebabkan terjadinya perceraian.

4. Orang tua hendaknya meningkatkan ibadahnya kepada Allah agar senantiasa memahami bahwa anak 
adalah titipan dari Allah yang perlu dijaga.

\section{DAFTAR PUSTAKA}

Abdullah, Nandiyah. (2013). Mengenal Anak Berkebutuhan Khusus. Magistra, 86 (25), 1-10. Diperoleh pada 5 November 2017, dari Fakultas Psikologi UNWIDHA Klaten.

Andesta, N. (2017). Pengalaman Keagamaan Anak Berkebutuhan Khusus (Studi di SLB A Bina Insani Kelurahan Gedung Meneng Kecamatan Rajabasa Bandar Lampung). Skripsi. Universitas Islam Negeri Raden Intan Lampung. Diperoleh dari http://repository.radenintan.ac.id/1078/1/SKRIP SI_Andesta.pdf.

Anggraeni, R.R. (2013). Persepsi Oran Tua Terhadap Anak Berkebutuhan Khusus (Deskriptif Kuantitatif di SDLB N.20 Nan Balimo Kota Solok). Jurnal Ilmiah Pendidikan Khusus. 1(0): 258-265.

Aniello, J.S.D \& Cipriani, A.N. (2011). The Divorce Case Involving Children with Special Needs. New Jersey Family Lawyer. 32(2): 5761

Apostelina, E. (2012). Resiliensi Keluarga Pada Keluarga Yang Memiliki Anak Autis. Jurnal Penelitian dan Pengukuran Psikologi. 1(1): 164-176.

Bernardi, F \& Radl, J. (2014). The long-term consequences of parental divorce for children's educational attainment. Demographic Research. 30(61): 1653-1680.

Harley, S.L.,Barker, $\quad$ E.T.,Seltzer, M.M.,Greenberg, J.,Floyd, F.,Orsmond, G.,Bolt, D. (2010). The Relative Risk and Timing of Divorce in Families of Children With an Autism Spectrum Disorder. Journal of Family Psychology. 24(4): 449-457.

Darmono, A. (2015). Peran Orang Tua Dalam Pendidikan Anak Berkebutuhan Khusus. Sekolah Tinggi Agama Islam (STAI) Ngawi. Diperoleh dari http://ejournal.iaingawi.ac.id/index.php/almabs ut/article/view/21.
Desiningrum, D.R. (2016). Psikologi Anak Berkebutuhan Khusus. Yogyakarta: Psikosain.

Eymann, A., Busaniche, J., Llera, J., De Cunto, C., \& Wahren,C. (2009) Impact of divorce on the quality of life in school-age children. Jornal de Pediatria (Rio J). 85(6):547-552.

Faradina, N. (2016). Penerimaan Diri Orang Tua Yang Memiliki Anak Berkebutuhan Khusus. EJournal Psikologi. 4(4): 386-396.

Farida. (2015). Bimbingan Keluarga Dalam Membantu Anak Autis (Kehebatan motif Keibuan). Jurnal Bimbingan Konseling Islam. 6(1): 63-88.

Green, J. (2010). Divorce Therapy: Helping Families Separate and Reorganize.

Haenudin. (2013). Pendidikan Anak Berkebutuhan Khusus Tunarungu. Jakarta: Luxima Metro Media.

Hidayati, N. (2011). Dukungan Sosial bagi Keluarga Anak Berkebutuhan Khusus. INSAN. 13(1): 12-20.

Idrus, M. (2013). Layanan Pendidikan Bagi Anak Gifted. Jurnal Bimbingan dan Konseling "Psikopedagogia". 2(2): 116-131.

Iswari, M. (2007). Kecakapan Hidup Bagi Anak Berkebutuhan Khusus. Jakarta : Depdiknas.

Masruroh, H \& Widayat, I.W. (2014). Strategi Orangtua dalam Mengembangkan Kreativitas Anak Gifted. Jurnal Psikologi Pendidikan dan Perkembangan. 3(3): 213-220. Diperoleh dari http://journal.unair.ac.id/download-fullpapersjppp4474ac4781full.pdf.

Millata, D.N \& Satya D.R. (Tanpa Tahun). Hubungan Dukungan Keluarga Dengan Penyesuaian Penyesuaian Fungsi Sosial Anak Down Syndrom Usia 6-12 Tahun. Diperoleh dari http://www.stikeshangtuah-sby.ac.id/.

Nandia, K.P. (2015). Hubungan Dukungan Keluarga Dengan Kemampuan Sosial dan Emosional Anak Berkebutuhan Khusus (ABK): Tunarungu Di SDLB-B Karya Mulia 1 Surabaya. Skripsi. Universitas Katolik Widya Mandala Surabaya. Diperoleh dari http://repository.wima.ac.id/3794/1/Abstrak.pdf 
Nasrawaty. (2016). Peran Orang Tua Dalam Pendidikan Anak Berkebutuhan Khusus di SLB AC Mandara kendari (Studi Kasus Tunanetra dan Tunagrahita). Skripsi. Universitas Haluoleo Kendari. Diperoleh dari http://www. sitedi.uho.ac.id/.

Novita, S.E.M. (2015). Konseling Keluarga Dalam Menghadapi Problem Perceraian (Studi kasus di Biro Konsultasi dan konseling Keluarga Sakinah Al-Falah). Skripsi. Universitas Islam Negeri Maulana malik Ibrahim Malang. Diperoleh dari http://etheses.uinmalang.ac.id/7185/1/11210089.pdf.

Rahman, M.M. (2015). Memahami Prinsip Pembelajaran Anak Berkebutuhan Khusus. Jurnal STAIN Kudus. Diperoleh dari http://journal.stainkudus.ac.id/.

Sidik, J. (2014). Gambaran Dukungan Keluarga Yang Memiliki Anak Berkebutuhan Khusus Di Sekolah Khusus Kota Tangerang Selatan. Skripsi. Universitas Islam Negeri Syarif Hidayatullah.

Sobsey, D. (2004). Marital stability and marital satisfaction in families of children with disabilities: Chicken or egg? Developmental Disabilities Bulletin. 32(1): 62-83

Suparno. (2007). Pendidikan Anak Berkebutuhan Khusus. Konsorsium Program S1 PGSD: Direktorat Jendral Pendidikan Tinggi.

Supriyanto, A. (2012). Peran Pengasuhan Orangtua Anak Berkebutuhan Khusus Dalam Aktivitas Olahraga. Proceeding Seminar Nasional 3-5 Des 2012 di Hotel Aggas Surakarta. Diperoleh dari http://staffnew.uny.ac.id.

United Nations Educational, Scientific and Cultural Organization. (2015). Teaching Children with Disabilities in Inclusive Settings. Bangkok: UNESCO Bangkok Office.

Yusuf, M. (2014). Dampak Perceraian Orang Tua Terhadap Anak. Jurnal Al-Bayan. 20(29): 33-44.

Yuwono, J. (2012). Memahami Anak Autis (Kajian Teori dan Empirik). Bandung: Penerbit Alfabeta. 